\title{
Synaptic Plasticity in the Hippocampus: Effects of Estrogen from the Gonads or Hippocampus?
}

\author{
G. M. Rune $\cdot$ C. Lohse $\cdot$ J. Prange-Kiel $\cdot$ L. Fester \\ M. Frotscher
}

Published online: 29 September 2006

(C) Springer Science+Business Media, LLC 2006

\section{Erratum to: Neurochem Res \\ DOI 10.1007/s11064-005-9004-8}

The following errors (listed by section, paragraph, and sentence) were published in this article.

\footnotetext{
Abstract

In the first sentence "has" should be changed to "have".

\section{Results and discussion}

Endocrine regulation of synaptic plasticity by estradiol

In the beginning of the third to the last sentence of the first paragraph ("It is well known that steroids...") the word "are" should be deleted.

"of estradiol" should be added to the beginning of Fig. 1 legend so that it should read: "Effects of physiological doses of estradiol".
}

The online version of the original article can be found at http://www.dx.doi.org/10.1007/s11064-005-9004-8

G. M. Rune $(\square)$ · C. Lohse · J. Prange-Kiel .

L. Fester

Zentrum für Experimentelle Medizin,

Institut für Anatomie I: Zelluläre Neurobiologie,

Universitätsklinikum Hamburg-Eppendorf,

Martinistr. 52, D-20246 Hamburg, Germany

e-mail: rune@uke.uni-hamburg.de

\section{Frotscher}

Institute of Anatomy and Cell Biology,

Albert-Ludwigs-Universität Freiburg,

Albertstr. 17, D-79104 Freiburg,

Germany "and control animals" should be added to the end of Fig. 1 legend so that it should read: "estradiol and control animals".

In the first half of sentence 5, paragraph 3: "transaction" should be changed to "transection".

Paracrine regulation of synaptic plasticity by estradiol

"after" should be added to the end of the last sentence in paragraph 2 so that it should read: "as early as after 3 days of treatment".

Effects of high doses of exogenous estradiol

"transfected cells" should be deleted from Fig. 7 legend.

"in" should be changed to "on" at the end of the last sentence in paragraph 2 so that it should read: "on the number of spine synapses and boutons". 